\title{
Comparison of liver regeneration in laparoscopic versus open right hemihepatectomy for adult living donor liver transplantation
}

\author{
Jaehun Yang, Jong Man Kim, Jinsoo Rhu, Sangjin Kim, Seohee Lee, Gyu-Seong Choi, and Jae-Won Joh
}

\author{
Department of Surgery, Samsung Medical Center, Sungkyunkwan University School of Medicine, Seoul, Korea
}

Backgrounds/Aims: This study aims to compare differences between laparoscopic donor right hemihepatectomy (LDRH) and open donor right hemihepatectomy (ODRH) in the quality of the operation, postoperative complications, and liver regeneration measured via volumetry. Methods: This study included 119 patients who underwent living donor right hemihepatectomy at Samsung Medical Center from January 2016 to December 2017. We compared several aspects of LDRH and ODRH and analyzed the results using the independent t-test, chi-square test and Fisher's exact test. Results: Among 119 enrolled patients, 66 patients (55.5\%) underwent open surgery, and 53 patients (44.5\%) underwent laparoscopic surgery. The mean operation time was significantly shorter for ODRH $(290.57 \pm 54.04$ minutes) than LDRH $(312.28 \pm 53.5$ minutes $)(p=0.031)$. Estimated blood loss was significantly less in LDRH $(258.49 \pm 119.99 \mathrm{ml})$ than ODRH $(326.52 \pm 157.68 \mathrm{ml})(p=0.011)$. The remnant liver recovered to $83.35 \pm 10.71 \%$ of the preoperative estimate whole liver volume (pre-EWLV) in the ODRH group and $84.04 \pm 8.98 \%$ of the pre-EWLV in the LDRH group ( $p=0.707)$. The percentage of increased estimated liver volume to postoperative estimate remnant liver volume (post-ERLV) was $137.62 \pm 40.34 \%$ in the ODRH group and $130.56 \pm 36.78 \%$ in the LDRH group, and there was no statistically significant difference between the two groups $(p=0.326)$. An analysis of postoperative complications showed no significant differences. Conclusions: LDRH is safe, and there is no significant difference in hepatic regeneration compared with ODRH. Therefore, LDRH can be applied for living donation of liver. (Ann Hepatobiliary Pancreat Surg 2020;24:33-37)

Key Words: Living donor right hemihepatectomy; Laparoscopic donor right hemihepatectomy; Liver transplantation; Liver regeneration; Volumetry

\section{INTRODUCTION}

Liver transplantation is the most definitive treatment for patients with end-stage liver disease. However, compared to the number of patients who require liver transplantation, the number of livers from deceased patients are limited. For this reason, living donor liver transplantation (LDLT) has emerged as an alternative. ${ }^{1}$ Since the first successful LDLT was performed with pediatric recipients in $1989,{ }^{2}$ LDLT has developed rapidly. ${ }^{3}$

The laparoscopic approach to hepatectomy has become popular in recent years as it is associated with less pain and is cosmetically acceptable. ${ }^{4}$ Therefore, laparoscopic hepatectomy has been widely performed in several centers over the past two decades. Based on our experience with laparoscopic hepatectomy, we have applied this experi- ence to adult living donor right hemihepatectomy. ${ }^{5}$

On the other hand, the debate over the safety of laparoscopic hepatectomy is ongoing, and this reality is more apparent in donor hepatectomy. ${ }^{6}$

We previously reported our experiences with laparoscopic donor hepatectomy for adult LDLT recipients. ${ }^{7}$ Since then, our experience has accumulated, and the surgery quality has improved. Currently, we perform more LDRH than ODRH in our center, but LDRH and ODRH have been performed in parallel for the last two years.

This study aimed to compare several differences between LDRH and ODRH during this transient two-year period and measurements includes the quality of the operation, postoperative complications, and liver regeneration measured via volumetry.

Received: November 14, 2019; Revised: November 16, 2019; Accepted: November 18, 2019

Corresponding author: Jong Man Kim

Department of Surgery, Samsung Medical Center, Sungkyunkwan University School of Medicine, 81 Irwon-ro, Gangnam-gu, Seoul 06351, Korea Tel: +82-2-3410-1719, Fax: +82-2-3410-0040, E-mail: yjongman21@gmail.com

Copyright (C) 2020 by The Korean Association of Hepato-Biliary-Pancreatic Surgery

This is an Open Access article distributed under the terms of the Creative Commons Attribution Non-Commercial License (http://creativecommons.org/ licenses/by-nc/4.0) which permits unrestricted non-commercial use, distribution, and reproduction in any medium, provided the original work is properly cited. Annals of Hepato-Biliary-Pancreatic Surgery • pISSN: 2508-5778 - eISSN: 2508-5859 


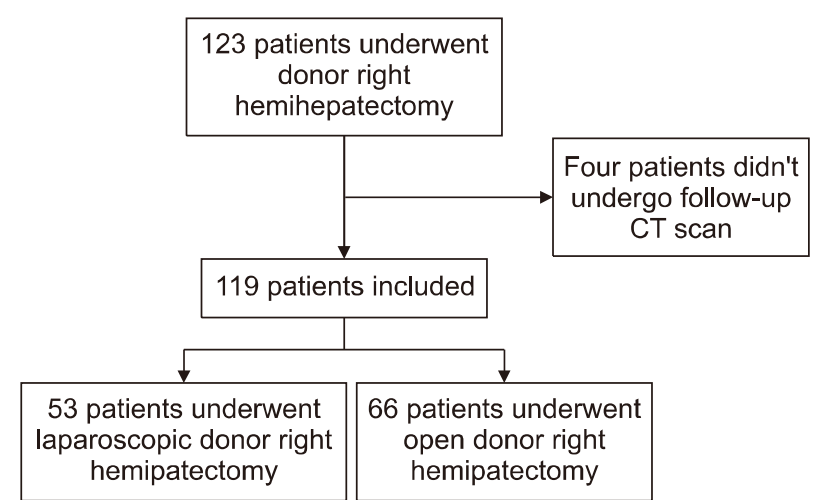

Fig. 1. Flow chart of patient enrollment. CT, computed tomography.

\section{PATIENTS AND METHODS}

\section{Study population}

This study was a single-center, nonrandomized, retrospective, comparable analysis between ODRH and LDRH. We evaluated 123 patients who underwent living donor right hemihepatectomy at Samsung Medical Center from January 2016 to December 2017. The medical records of 123 patients were analyzed, and four patients were excluded because they didn't undergo a follow-up computed tomography (CT) scan (Fig. 1). This study was approved by the Institutional Review Board of Samsung Medical Center (IRB no. 2019-08-110).

\section{Evaluation of liver volumetry}

A follow-up CT scan was performed between 2 and 3 months after donor right hemihepatectomy. The CT scans covered the liver at a section thickness of $2.5 \mathrm{~mm}$. The liver volume was estimated using manual methods: summation of the obtained volume by multiplying the area of the manual tracking area in each slice by the reconstruction interval.

\section{Analysis of volumetry}

A preoperative CT scan was utilized to calculate the preoperative estimate whole liver volume (pre-EWLV) and the postoperative estimate remnant liver volume (post-ERLV, same as preoperative estimate left liver volume). A follow-up CT scan approximately 2 months after surgery was used to determine the future estimate remnant liver volume (FERLV). We compared pre-EWLV and FERLV, and we calculated the percentage of increased liver volume as follows: $\{($ FERLV - post-ERLV) / postERLV $\} \times 100(\%)$.

\section{Statistical analysis}

Means and standard deviations were calculated for numerical variables. Continuous variables were analyzed using the independent t-test, chi-square test and Fisher's exact test. Two-tailed $p$ values less than 0.05 were considered statistically significant. The statistical analysis was performed using SPSS software version 25.0.

\section{RESULTS}

Among 119 patients who underwent living donor right hemihepatectomy during the study period, 66 patients (55.5\%) underwent open surgery and 53 patients (44.5\%) underwent laparoscopic surgery.

Donor characteristics and variables, including age, sex, body mass index and underlying disease (hypertension and diabetes mellitus), were similar for the ODRH group and the LDRH group (Table 1).

The results on operation quality are shown in Table 2. The mean operation time was signigicantly shorter for ODRH (290.57 \pm 54.04 minutes) than LDRH $(312.28 \pm 53.5$ minutes) $(p=0.031)$, although the gap of the mean operation time was only about 22 minutes.

Estimated blood loss was significantly less in LDRH $(258.49 \pm 119.99 \mathrm{ml})$ than ODRH $(326.52 \pm 157.68 \mathrm{ml})(p=$ $0.011)$.

No blood transfusions were administered to patients in either group.

A comparison of FERLV and pre-EWLV revealed that the remnant liver recovered to $83.35 \pm 10.71 \%$ of the pre-EWLV in the ODRH group and $84.04 \pm 8.98 \%$ of the pre-EWLV in the LDRH group $(p=0.707)$ (Table 3$)$.

A calculation of the percentage of increased estimated liver volume to post-ERLV showed a $137.62 \pm 40.34 \%$ in the ODRH group and a $130.56 \pm 36.78 \%$ increase in the LDRH group. There was no statistically significant difference between the two groups $(p=0.326)$.

Finally, a comparison of postoperative complications showed that there were no significant differences between the two groups (Table 4). There was no postoperative in traabdominal bleeding in either groups during the study period. 
Table 1 Demographics and characteristics of right liver donors for LDLT

\begin{tabular}{lccc}
\hline & $\begin{array}{c}\text { Open }(\mathrm{n}=66) \\
\text { Mean } \pm \text { SD }\end{array}$ & $\begin{array}{c}\text { Laparoscopic }(\mathrm{n}=53) \\
\text { Mean } \pm \text { SD }\end{array}$ & $p$ value \\
\hline Age (years) & $35.70 \pm 12.71$ & $32.79 \pm 11.92$ & 0.205 \\
Sex (male) & $36(54.5 \%)$ & $25(47.2 \%)$ & 0.424 \\
BMI & $23.64 \pm 2.68$ & $23.49 \pm 2.79$ & 0.776 \\
HTN & $1(1.5 \%)$ & $1(1.9 \%)$ & 1.000 \\
DM & 0 & $1(1.9 \%)$ & 0.445 \\
\hline
\end{tabular}

BMI, body mass index; HTN, hypertension; DM, diabetes mellitus

Table 2 Operative characteristics of adult living donor right hemihepatectomy

\begin{tabular}{llcc}
\hline & $\begin{array}{c}\text { Open }(\mathrm{n}=66) \\
\text { Mean } \pm \text { SD }\end{array}$ & $\begin{array}{c}\text { Laparoscopic }(\mathrm{n}=53) \\
\text { Mean } \pm \mathrm{SD}\end{array}$ & $p$ value \\
\hline Operative time $(\mathrm{min})$ & $290.57 \pm 54.04$ & $312.28 \pm 53.5$ & 0.031 \\
Estimated blood loss $(\mathrm{ml})$ & $326.52 \pm 157.68$ & $258.49 \pm 119.99$ & 0.011 \\
\hline
\end{tabular}

Table 3 Analysis of liver regeneration assessed by the estimate volumetry of CT scan after adult living donor right hemihepatectomy

\begin{tabular}{lccc}
\hline & Open $(\mathrm{n}=66)$ & Laparoscopic $(\mathrm{n}=53)$ & $p$ value \\
& Mean \pm SD & Mean \pm SD & 0.454 \\
Pre-EWLV $\left(\mathrm{cm}^{3}\right)$ & $1194.96 \pm 237.60$ & $1163.51 \pm 213.30$ & 0.655 \\
Post-ERLV $\left(\mathrm{cm}^{3}\right)$ & $424.36 \pm 96.84$ & $433.49 \pm 125.49$ & 0.772 \\
FERLV $\left(\mathrm{cm}^{3}\right)$ & $985.18 \pm 22.97$ & $974.93 \pm 27.01$ & 0.707 \\
Liver regeneration ratio (\%) & $83.35 \pm 10.71$ & $84.04 \pm 8.98$ & 0.326 \\
Increased volume ratio (\%) & $137.62 \pm 40.34$ & $130.56 \pm 36.78$ & \\
\hline
\end{tabular}

CT, computed tomography; Pre-EWLV, preoperative estimate whole liver volume; Post-ERLV, postoperative estimate remnant liver volume; FERLV, future estimate remnant liver volume; Liver regeneration ratio, (FERLV/pre-EWLV) $\times 100(\%)$; Increased volume ratio, $\{($ FERLV - post-ERLV)/post-ERLV $\} \times 100(\%)$

Table 4 Complications after adult living donor right hemihepatectomy

\begin{tabular}{lccc}
\hline & $\begin{array}{c}\text { Open }(\mathrm{n}=66) \\
\text { Mean } \pm \text { SD }\end{array}$ & $\begin{array}{c}\text { Laparoscopic }(\mathrm{n}=53) \\
\text { Mean } \pm \text { SD }\end{array}$ & $p$ value \\
\hline Bleeding & $0(0.0 \%)$ & $0(0.0 \%)$ & - \\
Wound complication & $9(13.6 \%)$ & $2(3.8 \%)$ & 0.109 \\
Biliary complication & $1(1.5 \%)$ & $5(9.4 \%)$ & 0.087 \\
Fluid collection & $2(3.0 \%)$ & $2(3.8)$ & 1.000 \\
Others & $1(1.5 \%)$ & $0(0.0 \%)$ & 1.000 \\
Total complication & $12(18.2 \%)$ & $9(17 \%)$ & 1.000 \\
\hline
\end{tabular}

Wound complications included resuturing or restapling due to seroma, hematoma, and dehiscence and occurred in nine cases $(13.6 \%)$ in the ODRH group and two cases $(3.8 \%)$ in the LDRH group ( $p=0.109)$. Although the difference between the two groups was not statistically significant, the incidence of wound complications (wound seroma, hematoma, and infection) tended to be higher in the ODRH group. No wound complication cases required gen- eral anesthesia.

On the other hand, biliary complications tended to occur more frequently in the LDRH group (5 cases, 9.4\%) than in the ODRH group ( 1 case, $1.5 \%$ ), but this difference was not statistically significant $(p=0.087)$.

Two patients in each group suffered postoperative intraabominal fluid collections $3.0 \%$ in the ODRH group, $3.8 \%$ in the LDRH group, $p=1.000)$. 
One patient in the ODRH group required percutaneous catheter drainage insertion due to pleural effusion.

In total, 12 patients $(18.2 \%)$ in the ODRH group and nine patients $(17 \%)$ in the LDRH group had complications. One patient in the ODRH group had both an intraabdominal fluid collection and a pleural effusion.

\section{DISCUSSION}

Minimizing donor risk is the most important concern in living donor right hemihepatectomy. Our center started a LDLT program in 1996, and LDRH began in 2013. ${ }^{7}$ This study showed that LDRH is not significantly different from ODRH in hepatic regeneration and, most importantly, donor safety. In addition, the mean operative time in the LDRH group was about 22 minutes longer than in the ODRH group, but the estimated blood loss was significantly less in the LDRH group.

When compared to our previous study, this study revealed that the quality of LDRH has improved. Our previous study between May 2013 and February 2015 showed that the mean operative time of LDRH was 436 minutes, and the mean estimated blood loss was $300 \mathrm{ml}$. The mean estimated blood loss decreased to $258 \mathrm{ml}$ in this study; the quality of LDRH in our center has improved. In addition, the overall postoperative complication rate was $33.3 \%$ in the previous study, but it decreased to $17 \%$ in this study, demonstrating an improvement in donor safety as well. ${ }^{7}$

The present study demonstrated that LDRH is superior to ODRH in estimated blood loss and blood transfusion during surgery, findings consistent with other recent studies showing that LDRH results in less blood loss, better cosmesis, and complete donor rehabilitation without deterioration in donor safety. ${ }^{8,9}$

Prompt liver regeneration does occur in the donor. In fact, some studies have suggested that complete liver regeneration occurs within a matter of weeks after donation. ${ }^{10}$ Although other studies have utilized volumetry to assess liver regeneration after living donor right hemihepatectomy, ${ }^{11}$ few studies have used volumetry to compare liver regeneration between LDRH and ODRH. Baker et al. investigated liver regeneration at 3 months after donor hepatectomy and demonstrated that regeneration reached $86.8 \%$ (95\% confidence interval (CI): 75.6-97.9) for laparoscopic-assisted donor right hepatectomy and $73.4 \%$ (95\% CI: 67.6-79.1) for open donor right hepatectomy $(p=0.03) .{ }^{12}$ In the present study, we analyzed the results of volumetry to investigate two aspects. First, we calculated the percentage of FERLV to pre-EWLV to determine how much the remnant liver volume recovered to the original liver volume. Second, to assess how much the increased liver volume was compared to post-ERLV, we calculated the percentage of increased liver volume (FERLV - post-ERLV) to post-ERLV. We found that there was no significant difference in liver regeneration according to the surgical method, and we reported better results than other previous studies.

Donor safety is the greatest concern in LDLT, ${ }^{13,14}$ and many studies have reported the complications of donor right hemihepatectomy. ${ }^{15,16}$ In a previous study, donor hepatectomy showed $0.1-0.2 \%$ mortality and $25-35 \%$ morbidity in healthy individuals. ${ }^{17}$ Our study showed $0 \%$ mortality and $17.6 \%$ morbidity of living donor right hemihepatectomy, and there was no statistically significant difference between the two investigated techniques. However, biliary complications, a problem that must be solved for donor safety, remained. ${ }^{15}$ As our experience continues to grow, ${ }^{7}$ we expect our complication rate to continue to decrease.

Minimally invasive surgery, a technique applied to many divisions of surgery including colorectal surgery, is utilized in hemihepatectomy, and LDRH has many advantages, such as less pain, reduced incision-related complications, and better donor quality of life during the early postoperative period. ${ }^{18}$ Nguyen KT et al. ${ }^{19}$ reported that minimally invasive hepatic resection for benign and malignant liver lesions is safe, feasible, and provides significant benefits for patients, such as less blood loss, less narcotic requirements, and shorter length of hospital stay.

Our study had some limitations. First, this study was designed as a nonrandomized retrospective study at a single-center, so selection bias cannot be excluded. Second, the period of time for the follow-up CT scan was about two months. There is a possibility of a difference in results after longer follow-up periods, such as six months or one year. Third, the results for complications were reviewed based on events outside the clinical pathway rather than dividing by the Clavien-Dindo classification.

On the other hand, this study has many strengths. Our 
study is based on the results from surgeons with previous experience in laparoscopic hepatectomy who had reached a certain level on the learning curve. ${ }^{20,21}$ We compared patients who underwent either LDRH or ODRH during a transitional period in which both surgical techniques were practiced at the same time; we did not compare the past and the present. In addition, few previous studies compared LDRH and ODRH for liver regeneration after liver donation using liver volumetry, and finally, this study provided evidence to support donor safety.

In conclusion, according to our study, LDRH is safe, and there is no significant difference in morbidity or hepatic regeneration compared with ODRH. Therefore, LDRH can be applied to the living donation of liver.

\section{ORCID}

Jaehun Yang: https://orcid.org/0000-0002-6256-3103

Jong Man Kim: https://orcid.org/0000-0002-1903-8354

Jinsoo Rhu: https://orcid.org/0000-0001-9809-8525

Sangjin Kim: https://orcid.org/0000-0002-0080-176X

Seohee Lee: https://orcid.org/0000-0003-3570-7148

Gyu-Seong Choi: https://orcid.org/0000-0003-2545-3105

Jae-Won Joh: https://orcid.org/0000-0003-4823-6218

\section{AUTHOR CONTIRUBUTIONS}

Conceptualization: JY, JMK.

Data acquisition: JY, JMK, JR, SK, SL, GSC, JWJ.

Data analysis: JY, JMK, JR, SK, SL, GSC, JWJ.

Methodology: JY, JMK.

Project administration: JY, JMK, GSC, JWJ.

Visualization: JY, JMK.

Writing - original draft: JY.

Writing - review \& editing: JY, JMK.

\section{REFERENCES}

1. Chen KH, Siow TF, Chio UC, Wu JM, Jeng KS. Laparoscopic donor hepatectomy. Asian J Endosc Surg 2018;11:112-117.

2. Raia S, Nery JR, Mies S. Liver transplantation from live donors. Lancet 1989;2:497.

3. Tulla KA, Jeon H. Living donor liver transplantation: technical innovations. Gastroenterol Clin North Am 2018;47:253-265.

4. Martin RC, Scoggins CR, McMasters KM. Laparoscopic hepatic lobectomy: advantages of a minimally invasive approach. J Am Coll Surg 2010;210:627-634, 634-626.

5. Park JI, Kim KH, Lee SG. Laparoscopic living donor hepatectomy: a review of current status. J Hepatobiliary Pancreat Sci 2015;22:779-788.

6. Soubrane O, Gateau V, Lefève C. Is laparoscopic live donor hepatectomy justified ethically? J Hepatobiliary Pancreat Sci 2016; 23:209-211.

7. Kwon CHD, Choi GS, Kim JM, Cho CW, Rhu J, Soo Kim G, et al. Laparoscopic donor hepatectomy for adult living donor liver transplantation recipients. Liver Transpl 2018;24:1545-1553.

8. Samstein B, Griesemer A, Halazun K, Kato T, Guarrera JV, Cherqui D, et al. Pure laparoscopic donor hepatectomies: ready for widespread adoption? Ann Surg 2018;268:602-609.

9. Takahara T, Wakabayashi G, Nitta H, Hasegawa Y, Katagiri H, Umemura A, et al. The first comparative study of the perioperative outcomes between pure laparoscopic donor hepatectomy and laparoscopy-assisted donor hepatectomy in a single institution. Transplantation 2017;101:1628-1636.

10. Kawasaki S, Makuuchi M, Matsunami H, Hashikura Y, Ikegami $\mathrm{T}$, Nakazawa $\mathrm{Y}$, et al. Living related liver transplantation in adults. Ann Surg 1998;227:269-274.

11. Ibrahim S, Chen CL, Wang CC, Wang SH, Lin CC, Liu YW, et al. Liver regeneration and splenic enlargement in donors after living-donor liver transplantation. World J Surg 2005;29:16581666.

12. Baker TB, Jay CL, Ladner DP, Preczewski LB, Clark L, Holl $\mathrm{J}$, et al. Laparoscopy-assisted and open living donor right hepatectomy: a comparative study of outcomes. Surgery 2009;146: 817-823; discussion 823-825.

13. Ghobrial RM, Freise CE, Trotter JF, Tong L, Ojo AO, Fair JH, et al.; A2ALL Study Group. Donor morbidity after living donation for liver transplantation. Gastroenterology 2008;135:468476.

14. Goja S, Yadav SK, Saigal S, Soin AS. Right lobe donor hepatectomy: is it safe? A retrospective study. Transpl Int 2018;31: 600-609.

15. Lee JG, Lee KW, Kwon CHD, Chu CW, Kim BW, Choi DL, et al. Donor safety in living donor liver transplantation: the Korean organ transplantation registry study. Liver Transpl 2017; 23:999-1006.

16. Zhang B, Pan Y, Chen K, Maher H, Chen MY, Zhu HP, et al. Laparoscopy-assisted versus open hepatectomy for live liver donor: systematic review and meta-analysis. Can J Gastroenterol Hepatol 2017;2017:2956749.

17. Au KP, Chok KSH. Minimally invasive donor hepatectomy, are we ready for prime time? World J Gastroenterol 2018;24:26982709.

18. Makki K, Chorasiya VK, Sood G, Srivastava PK, Dargan P, Vij V. Laparoscopy-assisted hepatectomy versus conventional (open) hepatectomy for living donors: when you know better, you do better. Liver Transpl 2014;20:1229-1236.

19. Nguyen KT, Marsh JW, Tsung A, Steel JJ, Gamblin TC, Geller DA. Comparative benefits of laparoscopic vs open hepatic resection: a critical appraisal. Arch Surg 2011;146:348-356.

20. Kwon CHD, Choi GS, Joh JW. Laparoscopic right hepatectomy for living donor. Curr Opin Organ Transplant 2019;24:167-174.

21. Rhu J, Choi GS, Kim JM, Joh JW, Kwon CHD. Feasibility of total laparoscopic living donor right hepatectomy compared with open surgery: comprehensive review of 100 cases of the initial stage. J Hepatobiliary Pancreat Sci 2020;27:16-25. 